\title{
Cryobanking of human sperm
}

Mark S Frankel ${ }^{1}$ Program of Policy Studies in Science and Technology, George Washington University, Washington, DC, USA

This brief essay discusses some of the medical and social uses of banking human semen as well as many of the ethical issues which emerge from the application of this technology.

In 1953, Bunge and Sherman, using dry ice for freezing and storing semen, reported the first successful human pregnancy resulting from insemination with frozen human semen. Since that time, new and improved methods of freezing and storing semen by immersion in liquid nitrogen at $-196.5^{\circ} \mathrm{C}$ (Behrman and Ackerman, 1969) have improved the fertilizing capacity of frozen semen and led to the emergence of a number of commercial human sperm banks in the United States.

\section{Contemporary uses}

The primary use of frozen semen has been for the treatment of male infertility, in which case a 'donor's' semen may be used for insemination independently of time and place. An increase in demand for semen by infertile couples, who represent about 30 per cent of all marriages in the United States, was a contributing factor to the rapid growth of commercial semen banking. Another factor was the increasing popularity of vasectomy as a method of contraception. With the hope of freezing their semen for use at a later time, many men viewed semen banks as a way of ensuring future fertility.

As a medical procedure, human semen banking must be considered an experimental technique and this has led to publicly expressed caution against its widespread use. For example, the American Public Health Association has questioned the 'biologic potency and genetic adequacy' of human sperm frozen over a relatively long period of time. Moreover, the National Medical Committee of Planned Parenthood - World Population has argued that any promise of fertility 'insurance' by freezing and storing semen may mislead and persuade individuals to undergo vasectomy in a hasty manner without proper consideration of the consequences. This publicly expressed concern underscores the

1Present address: Department of Political Science, Wayne State University, Detroit, Michigan 48202,USA need to review the rapid growth of human semen banks and to ensure that individual and society's interests, however they may eventually be defined? are adequately protected.

\section{Informed consent}

The increasing availability of frozen semen for therapeutic and contraceptive purposes raise several ethical questions regarding the use of, and requirements for, informed consent. To protect the rights and welfare of all parties using frozen semen a consent agreement should be implemented. Yet, survey of American semen banks found no standard. procedures for obtaining the consent of eithef recipients or donors.

Properly executed consent becomes an issue if human semen banking as it applies to: I) the process of collecting, storing, and using semen fo 5 therapeutic purposes; 2) the use of semen banking as a method of population control; and 3) frozes semen for scientific research.

The emotional and social impact often accom 3 panying therapeutic (donor) insemination requires that prospective recipients be told of possible psychological reactions (Rubin, 1965). Recipients should be informed that there is no guarantee that pregnancy will result from the use of semen thai has been frozen and stored over a protracted perio of time. Since infertile couples will be anxious t£ consent to any procedure which promises them the slightest hope of conception, they will be particularly vulnerable to exploitation and it would be unethical to take advantage of their desperation by creating. false expectations. A recent report (Fiumara, 1972 of the transmission of gonorrhoea by artificiaP insemination and the possible transmission of genetic diseases raises additional problems. Some workers in charge of semen banks perform genetio screening tests and chromosome analyses as routines procedures; others rely on the more easily obtaine ${ }_{D}$ medical and genetic histories. Since a donor mas? not know that he is a carrier of a transmissibleo disease, should there be a requirement that consen $\vec{P}$ forms enumerate the specific medical tests that will be performed to determine the health of the dono and the quality of his semen? Is the recipient entitled to a genetic profile of the donor? If so, arê there certain genetic tests which should be required? By what criteria are these tests to be selected? The 
matter of genetic testing is complicated further by the fact that the majority of genetic diseases cannot yet be detected by screening tests. How, then, can society maximize the safety and well-being of the recipients and their potential offspring?

Since the hope of future fertility by semen cryopreservation may encourage some men to submit to vasectomy as a means of population control, there is the danger of exploiting these hopes among those least prepared psychologically to understand the implications of their act. For example, there is evidence which suggests that vasectomies are not always benign and may increase sexual and psychological difficulties among those not emotionally prepared for the operation (Wolfers, 1970). While proper counselling may eliminate some of these individuals, it is essential that all men (and their wives) be fully informed of the scientific knowledge regarding frozen semen banking, including a statement that there is at present no way of ensuring that their semen will maintain its fertilizing capacity following frozen storage.

Many workers with semen banks are using stored semen to conduct fertility research. This may lead to a conflict of interest for an investigator involved in such research who, at the same time, counsels his patients on the therapeutic/contraceptive benefits of banking semen. There have been instances in other fields of biomedical research where an overly ambitious investigator, in promoting his own scientific career, has failed to consider properly the best interests of his patients (Barber et al, 1973). It is imperative, therefore, that those planning to store their semen be informed of any research for which that semen may be used and its possible consequences. If it is to be used for other research additional consent should be obtained. For example, at least one commercial bank has suggested that semen be used for research relating to fertilization in vitro, the fertilization outside the body of the female of human egg by human sperm, and a procedure which raises a host of its own ethical and social issues (Ramsey, 1972). Yet, it is doubtful whether persons depositing their semen are made aware of this possibility by existing storage agreements or consent forms.

\section{Donor compensation}

Commercial semen banks rely primarily on paid donors and this commercialization of semen donations creates both ethical and biological problems. If semen is treated in practice as a commodity to be bought and sold, what will be the impact on prospective donors of blood, eyes, or vital organs? Will they simply be viewed as other disposable 'commodities' in the market place? Competition between semen banks may also lead to a search for the 'best' donors. To what extent, then, will the buying and selling price of frozen semen determine the quality of the product and its consequences for the recipient? Will this eventually lead to the day when a semen bank promises 'eugenically desirable semen' to the highest bidder? Furthermore, will remuneration be viewed by the donor as a sign that he no longer need be concerned with the consequences of his act? For example, will donors frequently sell their semen in order to maintain an already illicit drug habit? There is always the dreaded possibility that a person who continuously sells his semen to supplement his income may well have a history of taking drugs and be unlikely to acknowledge it. In any newly developing field of medical care such as human semen banking, there is bound to be a high level of ignorance and uncertainty on the part of consumers. The patient often has no choice but to trust the medical profession as well as others who provide his medical care. Furthermore, the patient establishes this fiduciary relationship knowing that he and his family may have to bear the biological, social, and economic consequences that may result from any misplaced trust. Commercial semen banking raises serious ethical questions regarding the trust between doctor and patient and the responsibilities of the physician and the commercial bank to the consumer.

\section{Commercial banks and some broader social issues}

The development of commercial semen banks also raises a host of broader ethical and social issues. For example, to what extent should a society which is already investing in ways to curb population growth simultaneously support an effort which would help infertile couples to have children? Should limits be placed on the number of children that could be conceived in this manner?

If techniques for identifying and separating female- and male-producing sperm can be developed, frozen semen banking would make it easier for couples to use artificial insemination for choosing the sex of their children (one can easily visualize a clever entrepreneur opening up a semen bank for this purpose). But should semen banking be used for such socially orientated purposes? The issue involves more than medical considerations. For example, would the free use of sex preselection techniques lead to an imbalanced sex ratio and an altering of birth order patterns, both of which may generate serious social and behavioural effects (Etzioni, 1968; Handler, 1970)? There is also the serious ethical question of the propriety of distributing basically inessential but highly valued medical resources.

By carefully selecting donors with regard to their genetic qualities, the storage of frozen semen could make available a wide range of genetic material for altering the genetic quality of the human species (Muller, 196r). This raises the question of how and 
by whom the determination should be made of those human qualities to be considered 'desirable', especially with regard to future generations which will live in different physical and social environments. What ethical responsibilities exist between generations in the context of this technological capability?

Specimens of semen from different donors also vary considerably in their ability to withstand the process of freezing, storing, and thawing. Thus, it is highly probable that some donors will father a greater proportion of progeny than would normally be expected with regard to their history of fertility. This disproportionate use of donors will increase the coefficient of inbreeding and could result in an increased incidence of recessive genetic diseases. For example, marriage between first cousins brings together one eighth of the total recessive genes carried by both individuals, and studies have demonstrated that the progeny of such marriages experience a higher-than-normal mortality and malformation rate (McLaren, 1973).

The potential use of semen bank technology for such social purposes creates biological and social consequences for a broad spectrum of society and poses serious ethical issues. With the sudden emergence of commercial semen banks, it is not too soon to begin to consider how society can best use this technological capability to serve truly human ends.

\section{References}

Barber, B, Lally, J, Makarushka, J, and Sullivan, DT (1973). Research on Human Subjects: Problems of Social Control in Medical Experimentation, p 76尺 (Russell Sage Foundation, New York).

Behrman, S J, and Ackerman, D R (1969). Freezê preservation of human sperm, American fournat of Obstetrics and Gynecology, 103, 654-61.

Bunge, R G, and Sherman, J K (1953). Fertilizing capacity of frozen human spermatozoa, Natur $\overline{\mathrm{D}}$ (Lond), 172, 767-68.

Etzioni, A (1968). Sex control, science and society Science, 161, 1 107-12.

Fiumara, N J (1972). Transmission of gonorrhoea by artificial insemination, British fournal of Venereag Diseases, 48, 308-09.

Handler, P (ed) (1970). Biology and the Future of Man p 22 Oxford University Press. London and New York.

McLaren, A (1973). Biological aspects of AID, î Wolstenholme, G E W, and Fitzsimmons, D (eds), Law and Ethics of AID and Embryo Transfer, Ciba Foundation Symposium 17 (new series), p 7 Associated Scientific Publishers, Amsterdam.

Muller, H J (196I). Human evolution by voluntaryo choice of germ plasm. Science, 134, 643-49.

Ramsey, P (1972). Shall we 'reproduce'? I The medical ethics of in-vitro fertilization, and II Rejoinders and future forecasts, fournal of the Americals Medical Association, 220, 1346-50 and 1480-85.

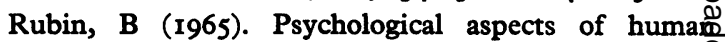
artificial insemination. Archives of Generab Psychiatry, 13, 121-32.

Wolfers, H (1970). Psychological aspects of vasectomy British Medical fournal, 4, 297-300. 